\title{
Ética: origens e distinção da moral
}

\section{Ethics: origins and the moral distinction}

\author{
Antônio Macena Figueiredo*
}

\begin{abstract}
Figueiredo AM. Ética: origens e distinção da moral. Saúde, Ética \& Justiça. 2008;13(1):1-9.
Resumo: Ética e moral são termos freqüentemente utilizados no cotidiano, porém, definir o que significam, não é tarefa fácil. Basta perguntar se existe alguma distinção entre esses vocábulos para constatarmos que as pessoas se vêem em dificuldade ao tentar explicar. Este artigo tem como objetivo apresentar alguns esclarecimentos teórico-filosóficos sobre a origem das divergências conceituais. Parte de uma breve revisão sobre as origens etimológicas dos termos ethos e mos. São apresentados os diversos sentidos em que esses vocábulos podem ser empregados, conceitos utilizados e finaliza com uma reflexão sobre a compreensão da ética como ciência específica ou como ramo de estudo da filosofia.
\end{abstract}

Descritores: Ética. Moral. Virtudes. Valores sociais.

\section{INTRODUÇÃo}

A ristóteles, que viveu entre os anos de 384-322 a.C., já afirmava que o homem é um animal político, o que remete à sua natureza social. Um século antes dessa afirmação, Heródoto, historiador grego, e Sófocles, um dos mais importantes escritores da tragédia, também já afirmavam que o homem sem a polis (cidade-Estado na Grécia antiga) teria um destino trágico, pois, embora seja um ser independente, sua existência só teria sentido com a convivência social ${ }^{1}$.
Fora do ambiente social, a existência do homem será sempre uma abstração, pois é dele que ele retira os meios de aprimoramento da vida coletiva, quer material, moral ou ético. Já dizia Aristóteles, em sua Ética a Nicômaco, que a ética nos ensina a viver, ela, para ser vivida, é práxis e não propriamente theoria ou póesis. Desse ensinamento se deduz que ética se instala em solo moral, uma vez que ela se depara com uma experiência histórico-social no terreno da moral. Daí a primeira definição: Ética

\footnotetext{
* Doutorando em Ciências da Saúde (UnB/DF), Mestre em Educação, Advogado, Enfermeiro, Especialista em Ética Aplicada e Bioética (Fiocruz); Professor de Ética Profissional da Universidade Federal Fluminense - UFF. Prof. do Curso de Especialização em Direito Médico e de atualização em Perícias Médicas da Faculdade de Direito da Universidade do Estado do Rio de Janeiro - UERJ. Presidente da Associação de Direito Médico e da Saúde do Estado do Rio de Janeiro - ADIMES-RJ. Membro da Comissão de Bioética e Biodireito da Ordem dos Advogados do Rio de Janeiro (OAB/RJ). Membro da Sociedade Brasileira de Bioética (Brasília-DF).

EndereÇo PARA contato: SGAN, Q. 912, Mod. C, apt. 07, Cep. 70.740-120. Brasília-DF. E-mail: macenaso@unb.br; macenaso@yahoo.com.br.
} 
ou filosofia da moral pode ser conceituada como a parte da filosofia que se ocupa com a reflexão a respeito dos fundamentos da vida moral ${ }^{2}$.

Mas o legado histórico desse conceito vem de longe, data de aproximadamente 500 a 300 anos a.C., época considerada como o período áureo do pensamento grego. Foi nesse período que surgiram muitas idéias e definições teóricas sobre a ética que até hoje fundamentam os conceitos histórico-sociais no campo da moral. Pensadores como Sócrates, Platão e Aristóteles foram os responsáveis pela análise e reflexão sobre o agir do homem ${ }^{3}$.

A reflexão grega neste campo surgiu de uma pesquisa a respeito da natureza do bem moral, na busca de um princípio absoluto de conduta ${ }^{3}$. Embora se tenha atribuído a Sócrates o início dessa reflexão, a primeira apresentação sistemática da Ética encontra-se em Aristóteles. Foi ele quem primeiro formulou os princípios da ação humana acerca da diferença entre o conhecimento teórico e o prático. Formulou a maior parte dos problemas que mais tarde passaram a ocupar a atenção dos filósofos morais: relação entre as normas e os bens; relação entre a ética individual e a social; classificação das virtudes; exames da relação entre a vida teórica e a vida prática, dentre outros.

Seguindo Aristóteles, muitas escolas, como, por exemplo, a Cínica (palavra originada do nome do ginásio Cinosargo de Atenas) e, em parte, a Estóica, ocuparam-se de estudar, principalmente, os fundamentos da vida moral do ponto de vista filosófico.

Uma das principais obras de Aristóteles foi $A$ ética de Nicômaco. Esse tratado é reconhecido como uma das obras-primas da filosofia moral. Nele, é apresentada a questão fundamental de toda a investigação ética ao se questionar: qual o fim último de todas as atividades humanas? Supondo Aristóteles que "toda arte e investigação, e igualmente toda ação e todo propósito, parecem ter em mira um bem qualquer: por isso foi dito, não sem razão, que o bem é aquilo a que todas as coisas visam"4.

Desse entendimento, deduz-se que a ética serve para conduzir as ações humanas a respeito das boas ações (virtudes) ou das não-éticas, às más (vícios). Pela forma de aquisição das virtudes, Aristóteles as classifica em: intelectuais (conhecimento teórico resultante do ensino) e morais (conhecimento prático - adquirido pelos hábitos). Daí define a ética como:

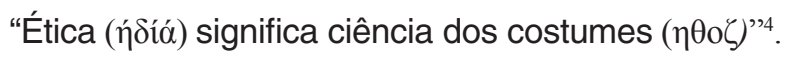

Desse contexto, extraíram-se as primeiras divergências entre os significados de ética e moral, a começar pela suas origens etimológicas e pelos vários sentidos que podem ser atribuídos a esses termos.

\section{2. ÉTICA}

Toda discussão sobre "ética" sempre se inicia pela revisão de suas origens etimológicas e pela sua distinção ou sinonímia com o termo "moral". Justifica-se a necessidade de explicitar a origem do termo ethos, uma vez que é de sua raiz primitiva que iremos encontrar as respostas para as ambigüidades terminológicas e imprecisões conceituais.

A palavra ethos expressa a existência do mundo grego que permanece presente na nossa cultura. Esse vocábulo deriva do grego ethos. Nessa língua, possui duas grafias: $\eta \theta 0 \zeta$ (êthos) e $\varepsilon \theta 0 \zeta$ (éthos). Essa dupla grafia não é gratuita, pois reúne uma diversidade de significados que, ao longo do tempo, distanciaram-se do seu sentido original ${ }^{5}$.

Considerando que, normalmente, os autores não costumam apresentar os significados desses termos em suas origens, antes de adentrarmos nos conceitos de "ética" e "moral", passaremos uma breve vista em suas origens, uma vez que as controvérsias sobre o que se entende por "ética" devem-se, em grande parte, aos diversos significados da palavra primitiva ethos e à sua tradução para o latim mos.

Esses dois termos podem ser entendidos em três sentidos: "morada" ou "abrigo", "caráter ou índole" e "hábitos" ou "costumes".

a. O termo grego $\eta \theta 0 \zeta$ (êthos), quando escrito com "eta" $(\eta)$ inicial, possui dois sentidos: morada, caráter ou índole.

O primeiro sentido é de proteção. É o sentido mais antigo da palavra. Significa "morada", "abrigo" e "lugar onde se habita". Usava-se, primeiramente, na poesia grega com referência aos pastos e abrigos onde os animais habitavam e se criavam. Mais tarde, aplicou-se aos povos e aos homens no sentido de seu país. Depois, por extensão, à morada do próprio homem ${ }^{6}$, isto é, refere-se a uma habitação que é íntima e familiar, é o "lar", um lugar onde o homem vive. É o lugar onde é mais provável de se encontrar o eu real. Ele representa aquilo que faz uma pessoa, um indivíduo: sua disposição, seus hábitos, seu comportamento e suas características. 
Figueiredo AM. Ética: origens e distinção da moral.

Nesse sentido, cada um tem sua própria ética. É isso, mais que os acidentes e incidentes da vida, que o diferencia de todos os demais ${ }^{7}$.

O segundo significado da palavra êthos assume uma concepção histórica a partir de Aristóteles. Representa o sentido mais comum na tradição filosófica do Ocidente. Este sentido interessa à ética, em particular, por estar mais próximo do que se pode começar a entender por ética. Êthos significa "modo de ser" ou "caráter". Mas esse vocábulo apresenta um sentido bem mais amplo em relação ao que damos à palavra "ética". O ético compreende, antes de tudo, as disposições do homem na vida, seu caráter, seus costumes e, naturalmente, também a sua moral. Na realidade, poderia se traduzir como uma forma de vida no sentido preciso da palavra, isto é, diferenciando-se da simples maneira de ser ${ }^{6}$.

Entretanto, é preciso ter certo cuidado com o uso da palavra "caráter", pois ela pode ter uma conotação filosófica, um sentido psicológico e outro restritamente moral. É este último que interessa à ética.

O caráter, segundo Heráclito de Éfeso (séc. VI-V a.C.) "é o conjunto definido de traços comportamentais e afetivos de um indivíduo, persistentes o bastante para determinar o seu destino"8. Para Kant (1724-1804), o caráter é entendido de acordo com a sua definição de causa, quer dizer, uma lei da causalidade, sob a qual as ações estariam ligadas integralmente 9 . Por outro lado, pode significar também o conjunto de traços psicológicos e/ou morais (positivos ou negativos) que caracterizam um indivíduo ou um grupo ${ }^{10}$.

Em sentido psicológico, "caráter é o conjunto de qualidades psíquicas e afetivas que intervêm na conduta de uma pessoa e a distinguem das demais, o que também chamamos de personalidade"10. Refere-se ao conjunto dos traços particulares, ao seu modo de ser, à sua índole e ao seu temperamento. Traços que estão mais ligados à estrutura biológica propriamente dita, ou seja, aquilo que é herdado mais pela natureza (páthos - do que é inato) do que os traços individuais adquiridos com a adaptação ao meio social.

Mas não é essa acepção da palavra que interessa à ética. Interessa o caráter em seu sentido estritamente moral, isto é, a disposição fundamental de uma pessoa diante da vida, seu modo de ser estável do ponto de vista dos hábitos morais (disposição, atitudes, virtudes e vícios) que a marcam - que a caracterizam - e lhe conferem a índole peculiar que a distingue dos demais ${ }^{10}$. Refere-se ao conjunto das qualidades, boas ou más, de um indivíduo, resultante do progressivo exercício na vida coletiva.

É esse caráter, não no sentido biológico ou psicológico, "senão no modo de ser ou forma de vida que vai adquirindo, apropriando, incorporando ao longo de toda uma existência", que está associado a ética 6 . Esse modo de ser, "apresenta uma dupla dimensão de permanência e de dinamismo. $O$ núcleo de nossa identidade pessoal é o produto das opções morais que vamos fazendo em nossa biografia. Essas opções vão conformando nossa fisionomia moral - a classe de pessoas que somos, nossa índole moral -, ou seja, a disposição para nos deixar mover por uns motivos e não por outros"10.

Diante das dificuldades de interpretação do conteúdo semântico da palavra ethos, não é sem motivo que os autores costumam simplificar. Definem a ética como sendo uma palavra derivada do grego ethos, que significa "modo de ser" ou "caráter" enquanto forma de vida adquirida ou conquistada pelo homem"11. Ou então, a "ética é derivado do grego ethikos - aquilo que se relaciona com o ethos ou caráter"12.

b. O segundo termo grego $\varepsilon \theta 0 \zeta$ (éthos), quando escrito com épsilon $(\varepsilon)$ inicial, é traduzido por "hábitos" ou "costumes"10.

Este é o éthos social. Significa hábitos, costumes, tradições. Refere-se aos atos concretos e particulares, por meio dos quais as pessoas realizam seu projeto de vida. Este sentido também interessa à ética, uma vez que o caráter moral vai se formando, precisamente, mediante as opções particulares que fazemos em nossa vida cotidiana ${ }^{10}$.

De maneira que é a força das tradições quem forma a identidade de uma sociedade. Reciprocamente, os hábitos constituem o princípio intrínseco dos atos. Conforme diz Aranguren" ${ }^{6}$, "parece haver um círculo êthos-hábitos-atos. Assim se compreende como é preciso resumir as duas variantes da acepção usual de êthos, estas sendo os princípios dos atos e aquele o seu resultado. Ethos é o caráter ( $\chi \alpha \rho \alpha \tau \rho \eta)$ cunhado, impresso na alma por hábitos"6.

Esta tensão, segundo Aranguren ${ }^{6}$, sem contradição entre êthos como caráter e éthos como hábitos, definiria o âmbito conceitual da idéia central da ética. Razão pela qual, tanto na concepção 
clássica quanto na moderna, a ética ocupa-se constantemente dos atos morais e dos hábitos no sentido de virtudes e vícios.

As virtudes podem ser classificadas pela forma de aquisição: intelectuais e morais. As virtudes intelectuais são resultados do ensino, são muito artificiais, por isso precisam de experiências e tempo para formar o caráter. As virtudes morais são adquiridas pelo hábito, costumes ou experiência. Não são inatas, são adquiridas pelo exercício da práxis, com o convívio social, ou seja, com a disposição de viver com ou conviver com os outros.

Sobre a distinção entre virtudes e vícios, explica $K$ orte $^{13}$ que as virtudes são as idéias ou razões positivas que trazem melhores resultados, ao passo que os vícios

são os portadores dos insucessos e dos resultados negativos. Enquanto atuo, seja de acordo com virtudes ou vícios, procedo eticamente. Mas, e aí vem o fundamento da explicação, se os costumes (mores) indicam a prática da virtude, e eu pratico o vício, eu estou agindo contra a moral, mas a rigor, não estou agindo contra a Ética mas contra as regras que me são recomendadas pelos conhecimentos trazidos pela Ética.

Por isso a ética pode ser entendida como a ciência da reta ordenação dos atos humanos desde os últimos princípios da razão (kathein). Estamos, portanto, diante de uma ciência prática, que trata de atos práticos. É a razão da filosofia da prática. É a forma que configura a matéria (atos humanos). Por isso, é importante saber que a ética não se ocupa do irracional, como sugerem algumas interpretações, senão do racional prático, intentando saber o específico da moral em sua razão filósofica ${ }^{5}$. Isto é, a razão das escolhas de uma determinada conduta e os fundamentos da tomada de decisão.

Dessa concepção e do entendimento de que ações humanas podem ser abordadas por uma perspectiva psicológica, biológica ou filosófica, deduz-se que a "ética" se ocupa da reflexão filosófica relativa à conduta humana sob o prisma dos atos morais. Ela vai examinar a natureza dos valores morais e a possibilidade de justificar seu uso na apreciação e na orientação de nossas ações, nas nossas vidas e nas nossas instituições ${ }^{14}$.

A ética estuda as relações entre o indivíduo e o contexto em que está situado. Ou seja, entre o que é individualizado e o mundo a sua volta [mundo moral]. Procura enunciar e explicar as regras [sobre as quais se fundamenta a ação humana ou razão pela qual se deve fazer algo], normas, leis e princípios que regem os fenômenos éticos. São fenômenos éticos todos os acontecimentos que ocorrem nas relações entre o indivíduo e o seu contexto ${ }^{13}$.

A ética filosófica, como compreende Cubelles ${ }^{5}$, é uma metalinguagem que fala da práxis humana, tentando descobrir a razão pela qual se deve fazer algo, considerando os valores morais estabelecidos em cada sociedade.

\section{Moral e Ética}

Outra discussão de relevo é sobre a distinção entre ética e moral. Instala-se aqui uma verdadeira confusão entre as similitudes e diferenças, a começar pelas definições dos dicionários de filosofia. Quanto à origem do termo, de acordo com o dicionário de filosofia de J. Ferrater Mora ${ }^{15}$, "a moral deriva de $\eta \theta 0 \zeta$ 'costumes', do mesmo modo que a 'ética', de $\eta \theta 0 \zeta$. Por vezes, a ética e a moral são usadas indistintamente, como disse Cícero (de fato, 1,1)"15.

Por isso, esse vocábulo é algumas vezes utilizado como sinônimo de ética. Entretanto, usa-se a palavra moral mais freqüentemente para designar códigos, condutas e costumes de indivíduos ou de grupos, como acontece quando se fala da moral de uma pessoa ou de um povo. Aí, é o equivalente da palavra grega ethos e da latina mores ${ }^{16}$.

Segundo o dicionário de filosofia de Nicola Abbagnano, o termo moral apresenta dois sentidos: o primeiro deriva do "lat. Moralia; in: Morals", fr. Morale; it. Morale; significa "o mesmo que Ética". Objeto da ética, conduta dirigida ou disciplinada por normas, conjunto dos mores. Neste significado, a palavra é usada nas seguintes expressões: ' $M$. dos primitivos', 'M. contemporânea' etc." No segundo sentido, deriva "lat. Moralis; in Moral".

\footnotetext{
Este adjetivo tem, em primeiro lugar, os dois significados correspondentes aos do substantivo moral: $1^{\circ}$ atinente à doutrina ética, $2^{\circ}$ atinente à conduta $e$, portanto, suscetível de avaliação M., especialmente de avaliação M. positiva. Assim, não só se fala de atitude $M$. para indicar uma atitude moralmente valorável, mas também coisas positivamente valoráveis, ou seja, boas ${ }^{17}$.
}

Não é sem motivo que Coimbra ${ }^{18}$ afirma que "ética e moral são sinônimos de origens distintas, que em si uma é a mesma coisa", isto é, possuem os 
mesmos sentidos. Por isso Tugendhat ${ }^{19}$ argumenta que não se pode tirar nenhuma conclusão do que se pode entender por ética e moral a partir das origens das palavras. De fato, etimologicamente, esses termos possuem idênticos conteúdos semânticos. Razão pela qual muitas vezes são empregados no cotidiano indistintamente.

As razões dessas divergências encontram-se, sem dúvida, nas origens das palavras, sobre as quais passaremos em revista, para depois apresentar alguns conceitos extraídos da literatura especializada.

O que ocorreu? No latim não existia uma palavra para traduzir o êthos, nem tampouco outra para representar o sentido do termo éthos, dado na língua grega. Então, na essência, esta distinção foi perdida. Ambas foram traduzidas por "mos" ou "mores" (plural de mos, do qual vem o termo moralis), pois era a palavra que mais se aproximava do sentido de ethos, que nessa língua pode significar tanto "costumes" como "caráter" ou gênero de vida.

Assim, "em latim, o "mos" passou a significar tanto o $\eta \theta 0 \zeta$ (êthos - morada, caráter, índole) como $\varepsilon \theta 0 \zeta$ (éthos - hábitos, costumes) costumes e hábitos"5. Está aqui a origem de toda a confusão acerca do conteúdo semântico dos termos e, por conseguinte, a sinonímia ou distinção dos sentidos que se atribui ao uso das palavras ética e moral.

Entretanto, este não é o único critério para se determinar o significado das palavras, pois assim como as línguas evoluem segundo a sua cultura, as palavras podem adquirir significados distintos de acordo com o sentido em que são empregadas. Além da dimensão semântica dos vocábulos e das expressões, há uma dimensão pragmática, visto que uma mesma palavra pode assumir significados diferentes num determinado contexto sócio-cultural.

Sobre esse aspecto, é preciso ater-se ao processo de evolução do sentido do termo como forma de conhecer não apenas o seu significado isolado mas, sobretudo, os vários sentidos em que pode ser utilizado numa dada cultura. Logo, questionar acerca do que se deve entender por ética ou moral, considerando apenas o conteúdo semântico dos termos, não é o único recurso de análise para se formularem significados, conceito ou definições.

Deixando um pouco de lado o esforço de se tentar deduzir uma definição exclusivamente a partir dos signos, vejamos as diversas maneiras de utilizar o termo "moral" e, por sua vez, de se chegar a um conceito correspondente ao contexto cultural.

A palavra moral, segundo Aranguren ${ }^{20}$, possui diferentes sentidos com referência direta ao comportamento humano e à sua classificação como moral ou, ao seu contrário, imoral; como parte da filosofia - filosofia moral. Moral, também escrita com maiúscula, quando se ocupa do comportamento humano no que se refere a bem ou mal.

Segundo Martinez ${ }^{21}$, o termo "moral" é utilizado atualmente de maneira distinta. Assim como ocorreu com os significados de ethos, essa multiplicidade de usos também deu lugar a alguns mal-entendidos. Para essa autora, algumas vezes o termo moral é empregado como substantivo e outras vezes como adjetivo. Como substantivo pode ser empregado em quatro situações:

1. Quando o termo "moral" for grafado com minúscula e estiver precedido do artigo definido feminino, "a moral", refere-se ao conjunto de princípios, preceitos, comandos, proibições, normas de conduta, valores e ideais de vida boa que, em seu conjunto, é constituído por um grupo humano concreto em uma determinada época histórica. Nesta acepção, a moral representa um modelo ideal de boa conduta socialmente estabelecida pela sociedade;

2. Quando a palavra "moral" é usada para fazer referência ao código pessoal de alguém. Por exemplo, quando se diz que "fulano possui uma moral muito rígida" ou quando se diz "beltrano carece de moral", estamos falando de um código moral que guia os atos de uma pessoa concreta ao longo de sua vida. É o conjunto de convicções e pautas de conduta que costuma constituir a base para os juízos morais que cada um faz das outras pessoas e de si mesmo;

3. Usa-se o termo "moral" com maiúscula (Moral) para referir-se a uma "ciência que trata do bem em geral, das ações humanas marcadas pela bondade ou pela malícia". A rigor, esta ciência não existe. $\mathrm{O}$ que existe é uma variedade de doutrinas como, por exemplo, a Moral católica, protestante, islâmica, budista, marxista etc ${ }^{21}$.

Fazendo um parêntese, lembramos que somente a ética na qualidade de disciplina filosófica (ciência da moral) possui teorias éticas diferentes e até opostas, pois há uma distinção entre uma doutrina e uma teoria: enquanto a doutrina trata de sistematizar um conjunto concreto de princípios, normas, preceitos e valores, as teorias constituem 
Figueiredo AM. Ética: origens e distinção da moral.

uma tentativa de explicar um fato ${ }^{21}$. As teorias representam um pensamento baseado num dado contexto histórico de uma época, sob o qual se fundamenta a vida moral concreta.

4. Quando a palavra moral se refere a expressões que a utilizam no masculino, tais como "ter o moral elevado" ou "estar com o moral alto" e outras semelhantes, moral torna-se sinônimo de "boa disposição do espírito", "ter força, coragem suficiente para enfrentar - com dignidade - os desafios que a vida nos apresenta. Essa acepção tem um profundo significado filosófico, pois a moral não é apenas um saber, nem um dever, mas sobretudo uma atitude e um caráter".

Com referência ao uso da palavra moral como adjetivo, a maioria das expressões está relacionada com a Ética. Neste caso há duas situações em que aparece como adjetivo ${ }^{21}$ :

1. Moral como oposto a "imoral" - Termo usado como termo valorativo de reprovação. Esse uso pressupõe a existência de algum código moral que serve de referência para emitir um juizo moral. Refere-se a uma conduta contrária às regras morais vigentes numa dada cultura;

2. Moral como oposto a "amoral - Termo usado para se referir a uma ação que não tem relação com a moralidade. A conduta dos animais, por exemplo, não tem nenhuma relação com a moralidade, pois pressupõe que estes não são responsáveis por seus atos. Ao passo que os seres humanos atingiram um desenvolvimento completo e, na medida em que tornam-se senhores de seus atos, têm uma conduta moral $^{22}$. Amoral, portanto, refere-se à "ação, atitude, estado ou caráter que não é nem moral nem imoral, i.e., que é exterior à esfera da moral"16.

Desses exemplos, é possível deduzir que, para a compreensão do que se deve entender por moral, as respostas não serão encontradas na origem do termo exclusivamente, pois os costumes ou a cultura de um povo antecedem as suas origens terminológicas. Os costumes são partes indissociáveis da identidade de um povo num dado contexto histórico. Neste contexto, e da análise pragmática de como as palavras adquirem vários sentidos, é que se poderá extrair um conceito mais apropriado ao seu uso.

Os termos "ética" e "moral" foram utilizados ao longo da história com diversos significados e com relações distintas entre si. Houve ocasiões em que os significados mudaram completamente. Jürgen
Habermas, por exemplo, com base em conceitos da tradição hegeliano-marxista, utiliza os termos "eticidade" e "moralidade" com significados novos, reservando a "moralidade" ao abstrato e universal e a "eticidade" à concreção no mundo da moralidade da vida ${ }^{10}$.

Assim como o termo ethos possui significados ambíguos, a palavra "moral" também pode ser empregada com sentidos diversos. Se olharmos o conceito de moral nos dicionários da língua portuguesa, notaremos que existe alguma distinção conceitual significativa. Segundo o dicionário Houaiss $^{8}$ :

\begin{abstract}
Moral - denota bons costumes, boa conduta, segundo os preceitos socialmente estabelecidos pela sociedade ou por determinado grupo social. Cada um dos sistemas de leis e valores estudados pela ética (disciplina autônoma da filosofia), caracterizados por organizarem a vida das múltiplas comunidades humanas, diferenciando e definindo comportamentos proscritos, desaconselhados, permitidos ou ideais.
\end{abstract}

Observa-se que o segundo conceito menciona que o sistema de leis (referindo-se a regras ou normas sociais) e valores são estudados pela ética. Daí a diferença entre os dois termos. "A Ética significa Ciência da moral, quer dizer, ética seria a construção intelectual, organizada pela mente humana sobre a moral. Esta seria, pois, o seu objeto" ${ }^{18}$.

"O entendimento clássico de ética era o do estudo filosófico dos fundamentos, dos princípios, dos deveres e dos demais elementos da vida moral. Ou seja, trata-se da teoria filosófica sobre a moralidade". O termo moral aplica-se, pelo contrário, à consideração prática dos casos concretos; isto é, para designar a arte de aplicar a teoria filosófica - a ética - aos problemas concretos da vida moral ${ }^{10}$.

Desse modo, não é apenas do significado restrito de um termo dissociado da cultura que se extrai um conceito mais exato. Claro que a discussão deve sempre começar pela análise lingüística, pois é a partir do significado primitivo que se extraem os primeiros significados.

Mas, afinal, o que entendemos por moral? A moral refere-se quer aos costumes, quer às regras de conduta admitidas numa sociedade determinada. Portanto, um fato moral é aceito para um tipo de sociedade de acordo com a sua tradição ou realidade cultural. A realidade moral, neste sentido, vai se referir ao conjunto desses costumes e 
dos juízos sobre os costumes que são objeto de observação ou de constatação segundo as regras sócio-culturais ${ }^{9}$.

Daí a compreensão de que a moral é conteúdo da ética. "Poder-se-ia dizer que a moral é a matéria prima da ética", pois constitui o conjunto de hábitos e prescrições de uma sociedade ${ }^{22}$.

A moral é o que se refere aos usos, costumes, hábitos e habitualidades. De uma certa forma, ambos os vocábulos [ética e moral] se referem a duas idéias diferentes, mas relacionadas entre si: os costumes dizem respeito aos fatos vividos, ao que é sensível e registrado no acervo do grupo social como prática habitual. A idéia contida na moral é a relação abstrata que comanda e dirige o fato, o ato, a ação ou o procedimento. A moral explica e é explicada pelos costumes. A moral pretende enunciar as regras, normas e leis que regem, causam e determinam os costumes, inclusive muitas vezes, anunciando-lhes as conseqüências ${ }^{13}$

À guisa de conclusão, deve-se entender por moral um sistema de normas, princípios e valores, segundo o qual são regulamentadas as relações mútuas entre os indivíduos ou entre estes com a comunidade de forma não coercitiva. De maneira que estas normas são dotadas de um caráter histórico e social e são acatadas de forma livre e por convicção de foro íntimo ${ }^{11}$.

\section{4. ÉTICA: CIÊNCIA OU RAMO DA FILOSOFIA?}

Diante da revisão das origens etimológicas e dos conceitos vistos anteriormente, interroga-se: a ética é uma ciência? Restringe-se apenas ao ramo de estudo da filosofia? Sendo ciência, que tipo de ciência seria a ética? Qual o seu objeto? Qual o seu objetivo? Qual o seu método de estudo?

Desde os gregos, a ética sempre constituiu uma parte do pensamento filosófico e sempre ocupou o ramo da filosofia, conhecido como teoria dos valores ou axiologia, que inclui a ética, a estética, a filosofia da religião, filosofia política e outras ${ }^{23}$. Por outro lado, pela ausência de desenvolvimento científico específico nas diversas áreas do conhecimento humano, a filosofia sempre se apresentou como um saber total. Ou seja, ela ocupava-se de quase tudo.

À medida que o conhecimento humano avançou, a abordagem científica estendeu-se progressivamente às novas realidades, inclusive à realidade social. A partir daí, vários ramos do saber se des- prenderam do tronco da filosofia para constituir ciências especiais com objeto específico, objetivos e métodos próprios ${ }^{11}$. Um dos últimos ramos que se desprendeu do tronco da filosofia foi a psicologia, seguindo o mesmo caminho de outras disciplinas, entre elas a ética - que era tradicionalmente considerada tarefa exclusiva dos filósofos ${ }^{11}$. Transformando-se numa ciência, pois tem objeto próprio, leis próprias e método próprio"22.

É considerada uma "teoria ou ciência do comportamento moral dos homens em sociedade. Ou seja, é a ciência de uma forma específica de comportamento humano" "'11. É a ciência do comportamento humano em relação aos valores, aos princípios e às normas ${ }^{24}$. Tem por objeto o estudo dos juízos de aprovação e desaprovação a respeito da conduta. Portanto, o seu objeto é a moral ${ }^{25}$.

Muito embora não seja um saber particular sobre um objeto de conhecimento, em virtude da complexidade das especulações que envolvem o comportamento humano, a ética afirma-se no solo filosófico. Não obstante alguns autores advoguem a idéia de sua autonomia científica, por ser essa uma parte do território de estudos filosóficos, ou seja, aquela que tem por principal foco de estudos a ação humana, necessariamente seu local de assento, seu berço natural é a filosofia prática ${ }^{26}$.

Assim como a filosofia divide-se em ramos de preocupações, a ética, enquanto um saber teórico, ocupa-se de três áreas fundamentais: ética descritiva, ética normativa e ética filosófica (ou Metaética). A ética descritiva é a ciência positiva dos fatos morais, sejam eles individuais ou coletivos ${ }^{10}$. Tem como função descrever os fenômenos morais ${ }^{24}$. A ética normativa trata dos juízos prescritivos com base nos códigos. Os sistemas normativos dizem como devem atuar os agentes morais, dando-lhes normas práticas de ação ${ }^{10}$. Por sua parte, faz-se oportuno esclarecer que "a ética é uma disciplina normativa, não por criar normas, mas por descobrilas e elucidá-las. Mostra à pessoa os valores e os princípios que devem nortear sua existência, pois a sua função é aprimorar seu sentido moral e influenciar a conduta"22. Por último, a ética filosófica se refere à reflexão moral. É a reflexão racional profunda dos pressupostos, dos fundamentos, dos sistemas de normas morais na busca de descobrir as verdades necessárias para que um sistema moral seja válido ${ }^{10}$.

Desse modo, a ética, enquanto conhecimento 
Figueiredo AM. Ética: origens e distinção da moral.

teórico, por se deparar com as práticas morais no contexto histórico-social, é considerada uma ciência social ${ }^{27}$. É uma ciência social porque o seu objeto de estudo é um fato socialmente histórico a moral. Já a moral não é concebida como ciência, senão o objetivo desta.

A guisa de conclusões escreve Sá25:

A ética é a ciência, tendo por objeto de estudo os sentimentos e juízos de aprovação e desaprovação acerca da conduta e da vontade humana, propondose a determinar: a. qual é o critério segundo a conduta e a vontade em tal modo aprovada se distinguem, ou ainda, qual é a norma, segundo a qual se opera e deve operar a vontade em tal conduta, e qual o fim que na mesma e para essa se cumpre e se deve cumprir; b. em que relações de valor estão, com observância daquela norma e obtenção daquele fim, as diversas formas de conduta, individual ou coletiva, tais como se apresentam na sociedade e na época à qual pertencemos ${ }^{25}$.

Sintetizando, enquanto conhecimento teóricofilosófico, ao contrário da moral, a grande preocupação da ética é esboçar as linhas gerais de uma teoria normativa que possa auxiliar na solução de problemas e na identificação do que é correto e de como devemos agir considerando os valores morais vigentes. Esse é o seu engajamento com a moral28.

\section{Considerações finais}

É possível deduzir que a análise etimológica dos termos não é suficiente para orientar-nos sobre o que devemos entender por ética e moral. Constatamos que a palavra ética tem particularidades conceituais de difícil precisão. Por isso, muitas vezes é confundida com moral e até mesmo empregada no cotidiano, no sentido de senso comum.

Outra questão que não é considerada no dia-adia é a distinção entre o uso substantivo ou adjetivo do termo "moral". Isso também pode levar a algumas imprecisões conceituais. Apesar da natural existência de uma sinonímia entre essas palavras, uma vez que ambas se referem à ação humana intencional e sobre os critérios de escolha de um determinado tipo de conduta, predomina o entendimento de que existe uma distinção, quer semântica, quer conceitual, entre ética e moral.

Por moral deve-se compreender "o conjunto de regras de condutas assumidas livre e conscientemente pelos indivíduos, com a finalidade de organizar as relações interpessoais, segundo os valores do bem e do mal" ao passo que a ética ou filosofia da moral "é mais abstrata, constituindo a parte da filosofia que se ocupa com a reflexão sobre as noções e os princípios que fundamentam a vida moral"29.

Reserva-se à ética o "estudo da moralidade do agir humano (bondade ou maldade dos atos humanos): sua retidão frente à ordem moral"21. A ética é a disciplina filosófica que investiga os diversos sistemas de morais elaborados pelos homens, buscando compreender a fundamentação das normas e proibições próprias a cada uma e explicar seus pressupostos, ou seja, as concepções sobre o ser humano e a existência que os sustenta.

É considerada uma ciência porque, além de se ocupar da reconstrução intelectual organizada pela mente humana acerca da moral, tem objeto próprio, leis próprias e método próprio. Seu objeto é a moral; e a reflexão teórico-filosófica, o condicionante metódico enquanto disciplina teórica.

Figueiredo AM. Ethos: origins and the moral distinction. Sáude, Ética \& Justiça. 2008;13(1):1-9.

Aвstract: Ethics and moral are terms frequently used in daily life, however to define what they mean is not an easy task. It is enough asking whether there is any distinction between these words to notice that people have difficulty trying to explain it. This article aims to present some theoretical-philosophical clarifications about the etymological origin of the terms ethos and mos. The diverse meanings in which these terms can be employed and the concepts used are presented. The article ends with a reflection about the comprehension of ethics as a specific science or as a branch of philosophical study.

Keywords: Ethics. Morale. Virtues. Social values. 


\section{REFERÊNCIAS}

1. Stone IF. O julgamento de Sócrates. Henriques Britto. São Paulo: Companhia das Letras; 2005. p.128.

2. Cotrim G. Fundamentos da filosofia: história e grandes temas. São Paulo: Saraiva; 1998. p. 243-303.

3. Valls AL. O que é ética. 8a ed. São Paulo: Brasiliense; 1994. p.7-21.

4. Aristóteles. A ética de Nicômaco. Tradução de Cássio M. Fonseca. 2a ed. São Paulo: Atena; 1944. v. 33, p.9-16.

5. Cubelles SC. Compêndio de ética filosófica e história de la ética. Valência: Edicep; 2002. p.16-7.

6. Aranguren JLL. Ética. 5a ed. Madri: Seleta; 1972. p.24-5-6.

7. Nicolescu B, et al. Educação e transdisciplinaridade. São Paulo: UNESCO, USP/Escola do Futuro, CESP; 2000. p.56.

8. Houaiss A. Dicionário Houaiss da língua portuguesa. Rio de Janeiro: Objetiva; 2001. p.620-1958.

9. Lalande A. Vocabulário técnico e crítico da filosofia. São Paulo: Martins Fontes; 1999. p.136-703.

10. Ferrer JJ, Ávarez JC. Para fundamentar a bioética: teorias e paradigmas teóricos na bioética contemporânea. São Paulo: Loyola; 2005. p. 25-6-7136-30.

11. Vázquez AS. Ética. 14a ed. Rio de Janeiro: Civilização Brasileira; 1993. p.14-49-52-16-12-235-243.

12. Palmer M. Problemas morais em medicina. São Paulo: Loyola; 2002. p.15.

13. Korte G. Iniciação à ética. São Paulo: Editora Juarez de Oliveira; 1999. p.1-64-115.

14. Skorupski J. Ética. In: Tsui-James EP, Nicholas B, organizadores. Compêndio de filosofia. São Paulo:
Loyola; 2002. p.196.

15. Mora JF. Dicionário de filosofia. São Paulo: Loyola; 2005. T-2 (E-J), p. 211.

16. Runes DD. Dicionário de filosofia. Lisboa: Presença; 1990. p.264-29.

17. Abbagnano N. Dicionário de filosofia. 5a ed. São Paulo: Martins Fontes; 2007. p.795.

18. Coimbra JAA. Fronteiras da ética. São Paulo: Senac; 2002. p.75.

19. Tugendhat E. Lições sobre ética. 5a ed. Petrópolis: Vozes; 1997.

20. Aranguren JLL. Propuestas morales. $4 a$ ed. Madrid: Seleta; 1994. p.23

21. Martins Filho IG. Manual esquemático de filosofia. 3a ed. São Paulo: LTr; 2006.p.13-15-6-7-231.

22. Naline J. Ética geral e profissional. 2a ed. São Paulo: Editora Revista dos Tribunais; 1999. p.73-34-35.

23. Reale M. Filosofia do direito. 19a ed. São Paulo: Saraiva; 1999. p.39.

24. Sgreccia E. Manual de bioética: fundamentos da ética e bioética. São Paulo: Loyola; 1996. p.139.

25. Sá AL. Ética profissional. 3a ed. São Paulo: Atlas; 2000. p.44.

26. BITTAR, ECB. Curso de ética jurídica: ética geral e profissional. 2a ed. São Paulo; 2004. p.14-5.

27. Motta NS. Ética e vida profissional. Rio de Janeiro: Âmbito Cultural; 1984. p.109.

28. Altoé A. Islã e os muçulmanos. Petrópolis: Vozes; 1989. p.10.

29. Aranha MLA, Martins MHP. Filosofando: introdução à filosofia. 3a ed. São Paulo: Moderna; 2005. p.218. 